\title{
MASYARAKAT SIPIL DAN MEKANISME ASEAN \\ INTERGOVERNMENTAL COMMISSION ON HUMANG RIGHTS: STUDI KASUS INTERNATIONAL HUMAN RIGHTS TREATY BODIES
}

\author{
Hadi Rahmat Purnama ${ }^{1}$
}

\begin{abstract}
Since the idea of establishment of AICHR began, the role of civil society in ASEAN has supported ASEAN for its commitments to establish human rights mechanism and Human Rights Body in Southeast Asia region. However, in 1995, ASEAN's commitments on human rights became less strong since states member of ASEAN grew with the inclusion of Vietnam, Cambodia, Laos and Myanmar. This condition gave set back to the development of politics in ASEAN. With this new development in ASEAN, the focus of civil society has grown in national and international level, which give wider influences. Civil society has given contribution to the development in international law through interpretation of international treaties, implementation of international law and enforcement of international law. In human rights issues, civil society has played important law in establishing institutions which based on international human rights treaties.
\end{abstract}

Keyword: human right, civil society, asean

\begin{abstract}
Abstrak
Sejak awal inisiatif pembentukan AICHR dimulai dengan peran masyarakat sipil di ASEAN yang mendorong ASEAN atas komitmentnya untuk membentuk mekanisme HAM di kawasan ASEAN dan membentuk Badan HAM ASEAN. Komitmen ASEAN terhadap HAM mengendur setelah tahun 1995 karena bertambahnya keanggotaan ASEAN dengan bergabungnya Vietnam, Cambodia, Laos dan Myanmar, sehingga menyebabkan kemajukan politik di ASEAN. Terkait dengan perkembangan baru ini, fokus dari masyarakat sipil telah berkembang dari tingkat nasional ke tingkat internasional yang bertujuan meberikan pengaruh yang lebih luas. Masyarakat sipil telah memberikan kontribusi terhadap perkembangan dalam hukum internasional melalui interpretasi perjanjian internasional, penerapan hukum internasional dan penegakan hukum internasional. Dalam masalah HAM, masyarakat sipil telah memainkan peranan yang penting terkait dengan badan yang telah dibentuk berdasarkan perjanjian internasional HAM.
\end{abstract}

Kata kunci: hak asasi manusia, masyarakat sipil, asean

\footnotetext{
${ }^{1}$ Penulis adalah Pengajar Hukum Internasional dan Hukum dan Hak Asasi Manusia, Fakultas Hukum Universitas Indonesia. Alamat kontak: hadirahmat@yahoo.com.
} 


\section{Latar Belakang}

Pada awal berdirinya Association of Southeast Asia Nations (ASEAN) di tahun 1967, Hak Asasi Manusia (HAM) bukanlah merupakan prioritas bagi ASEAN sehingga sama sekali tidak disebutkan dalam Deklarasi Bangkok yang membentuk ASEAN. Pada tanggal 20 November 2007, ASEAN Summit di Singapura ASEAN mengadopsi Piagam ASEAN yang kemudian berlaku pada tanggal 15 Desember 2008. Ini merupakan momentum penting bagi ASEAN yang telah berubah dari sebuah organisasi yang sangat longgar menjadi organisasi regional yang berdasarkan hukum. Piagam ASEAN memberikan kerangka kerja bagi ASEAN dan legal personality, ${ }^{2}$ serta memberikan dasar bagi komitmen ASEAN untuk membentuk institusi HAM regional. ${ }^{3}$

Dibandingkan dengan kawasan regional lain seperti Eropa, Amerika dan Afrika, lembaga dan mekanisme HAM Asia dapat dikatakan masih dalam tahap awal perkembangannya. Kawasan regional lain sudah lama membentuk dan mengembangkan institusi dan mekanisme HAM sebagai bagian dari organisasi regional mereka. ASEAN sebagai organisasi regional di Asia Tenggara merupakan organisasi regional yang baru belakangan membentuk Badan HAM ASEAN dan dapat dikatakan sebagai lembaga HAM pertama di kawasan Asia.

Sebelum ASEAN berfikir untuk membuat Badan HAM ASEAN, masyarakat sipil di ASEAN sudah memulai mendorong adanya mekanisme dengan membentuk Working Group for an ASEAN Human Rights Mechanism, pada tahun 1995 yang terdiri atas beberapa kelompok kerja nasional termasuk wakil dari pemerintah, parlemen, akademik, dan lembaga swadaya masyarakat. Lembaga ini dibentuk oleh Human Rights Committee of LAW ASIA. ${ }^{4}$ Kemudian disusul oleh Solidarity for Asian Peoples' Advocay (SAPA) membentuk Task Force on ASEAN and Human Rights (SAPA Task Force) dengan tujuan yang sama. ${ }^{5}$ Masyarakat sipil di ASEAN mengambil inisiatif ini karena komitmen ASEAN akan HAM mengendur pada tahun 1995 setelah bertambahnya anggota dan beberapa negara anggota ASEAN tertimpa krisis finansial.

Setelah menunggu sekian lama pada Oktober 2009, melalui Cha-Am Hua Hin Declaration On The Intergovernmental Commission On Human Rights, Term of Reference dari ASEAN Human Rights Body diadopsi pada ASEAN

${ }^{2}$ Chapter II, Article 3, Charter of the Association of Southeast Asian Nations, 20 November 2007 (the ASEAN Charter).

${ }^{3}$ Article 14, Ibid.

4 The Working Group for an ASEAN Human Rights Mechanism, About Us, $<$ http://www.aseanhrmech.org/aboutus.html>, diakses tanggal 14 Febuari 2012.

5 Report Solidarity for Asian Peoples Advocacy (SAPA) General Forum $<$ http://www.caramasia.org/enews/2007/march/inside/sapa/sapa_report.pdf $>$, diakses tanggal 28 Januari 2012. 
Summit ke-15 di Thailand dan ASEAN Interngovernmental Commission on Human Rights (AICHR) terbentuk. ${ }^{6}$ AICHR sebagaimana tertera di dalam TOR, adalah intergovernmental body ${ }^{7}$ dan sebagai badan konsultasi. AICHR mempunyai kewenangan untuk mempromosikan dan melindungi HAM. ${ }^{8}$ AICHR mempunyai tugas untuk merancang ASEAN Human Rights Declaration sebagai sistem hukum HAM regional yang mengikat. ${ }^{9}$

Hanya saja banyak kritik yang dikemukan oleh masyarakat sipil terhadap TOR AICHR, pertama prinsip-prinsip di ASEAN dimungkinkan menjadi penghalang bagi AICHR untuk melakukan investigasi terhadap pelanggaran HAM di negara anggota. ${ }^{10}$ Kedua, perwakilan yang ditunjuk oleh negaranegara anggota ASEAN adalah pejabat negara atau mantan pejabat negara dengan pengecualian perwakilan dari Indonesia, seorang aktivis HAM dan Thailand, seorang akademisi. ${ }^{11}$ Ketiga, pengambilan keputusan melalui konsensus berarti setiap negara dapat menolak kritik yang ditujukan kepada negaranya, sehingga dapat mengakibatkan deadlock atau pengadopsian posisi yang lemah atas isu HAM. ${ }^{12}$ Masyarakat sipil merasa bahwa kewenangan AICHR dalam perlindungan HAM sangat lemah, walaupun masyarakat sipil telah melakukan lobi untuk menjadikan AICHR sebagai sebuah institusi yang lebih mempunyai gigi dan kewenangan untuk melakukan ivestigasi terhadap pengaduan individual dan situasi HAM di suatu negara. ${ }^{13}$

AICHR menghadapi ujian pertamanya pada saat Pertemuan pertama AICHR di Jakarta pada bulan Maret 2010. Pada saat itu terdapat perimintaan dari keluarga jurnalis korban pembunuhan masal di Maguindanao, Philipina yang terjadi pada bulan November 2009, agar AICHR dapat melakukan invesitgasi atas kejadian tersebut. Tetapi AICHR menolak permintaan tersebut

${ }^{6}$ Cha-Am Hua Hin Declaration On The Intergovernmental Commission On Human Rights <http://www.aseansec.org/documents/Declaration-AICHR.pdf>, diakses tanggal 4 Maret 2012.

${ }^{7}$ Article 3, Term of Reference of ASEAN Intergovernmental Commission on Human Rights (TOR AICHR).

${ }^{8}$ Article 4.1, TOR AICHR.

${ }^{9}$ Article 4.2, TOR AICHR.

10 James Munro, The Relationship between the origins and regime design of the ASEAN Intergovernmental Commission on Human Rights (AICHR), The International Journal of Human Rights, 20 October 2010, p. 4-5.

11 Amnesty International Public Statement, ASEAN's new body must protect and promote human rights, <http:/www.amnesty.org/en/news-and-updates/news/asean-new-bodymust-protect-promote-human-rights-20090721>, diakses tanggal 28 Januari 2012.

${ }^{12}$ Yuval Ginbar, Human Rights in ASEAN- Setting Sail or Treading Water?, Human Rights Law Review 10:3 (2010), p. 514-515.

13 Ibid. 
dan AICHR menyatakan, seperti dikutip media, "Investigasi terhadap pengaduan individual bukan merupakan kewenangan dari AICHR", hal ini disampaikan kepada Naomi Parcon, istri korban pembataian di Mangindanao. Namun hal ini tidaklah tepat sebab tidak ada klausula di dalam TOR AICHR yang menghalangi AICHR untuk melakukan investigasi terhadap pelanggaran HAM. $^{14}$

Seharusnya AICHR membuat pertemuan dengan individu atau kelompok masyarakat yang memang mengingikan untuk menyampaikan pengaduan atau laporan atas pelanggaran HAM yang terjadi di kawasan ASEAN. Pelaporan, baik itu dalam bentuk pengaduan terkait dengan pelanggaran HAM, hukum nasional mereka, kebijakan atau praktek yang melanggar HAM, masalah HAM yang melewati lintas batas negara, atau masalah regional. AICHR seharusnya mempelajari dulu laporan-laporan tersebut secara menyeluruh dengan berhubungan dengan Komisi Nasional HAM di masing-masing negara atau dengan lembaga pemerintahan terkait sehingga pelanggaran HAM dapat diakhiri.

Sejak awal inisiatif pembentukan AICHR dimulai dengan peran masyarakat sipil di ASEAN yang mendorong ASEAN atas komitmentnya untuk membentuk mekanisme HAM di kawasan ASEAN dan membentuk Badan HAM ASEAN. Masyarakat sipil juga mencoba memberikan laporan atas terjadi pelanggaran HAM di negara-negara anggota ASEAN melalui pengaduan baik individual maupun kelompok. Seperti halnya, Treaty Bodies intenasional sudah memperaktekkan hal ini sejak lama. Bahkan masyarakat sipil mempunyai partisipasi yang aktif dan memberikan kontribusi yang cukup besar dalam perkembangan dari Treaty Bodies internasional untuk membuat mekanisme penyelesaian atas pelanggaran HAM yang terjadi di negara-negara.

\section{Permasalahan}

1. Bagaimakah peran masyarakat sipil di ASEAN dalam pembentukan ASEAN Interngovernmental Commission on Human Rights (AICHR)?

2. Bagaimakah hubungan Treaty Bodies dengan masyarakat sipil dalam pelaksanaan hak asasi manusia di suatu negara?

\section{Kerangka Teori}

Tulisan ini menggunakan istilah-istilah yang digunakan secara khusus, sebagai berikut:

1. Masyarakat Sipil sebagai terjemahan dari Civil society yang di dalamnya organisasi publik yang bukan merupakan institusi

14 ASEAN Human Rights Commission Stumbles At First Hurdle, $<$ http://theonlinecitizen.com/2010/03/asean-human-rights-commission-stumbles-at-firsthurdle/>, diakses tanggal 28 Januari 2012. 
pemerintahan termasuk media, lembaga pendidikan, institusi keagamaan, dan organisasi sukarela seperhalnya non-governmental organization/lembaga swadaya masyarakat.

2. Partisipasi Publik adalah bentuk hubungan yang terinstitusional antar masyarkat sipil dengan organisasi internasional atau regional yang independen dari system pemerintahan. Konsep ini mempunyai dua faktor yang saling berhubungan yaitu transparansi dan keterlibatan masyarakat sipil dalam pengambilan keputusan.

3. Treaty Bodies adalah UN Charter-based bodies, including the Human Rights Council, and bodies created under the international human rights treaties and made up of independent experts mandated to monitor State parties' compliance with their treaty obligations.

\section{Hak Asasi Manusia dan ASEAN}

Dalam Bangkok Declaration 1967, ${ }^{15}$ Hak Asasi Manusia (HAM) sama sekali tidak disebutkan, karena bukan merupakan suatu prioritas bagi negaranegara di kawasan Asia Tenggara yang ASEAN. Pernyataan ASEAN tentang HAM pertama kali dinyatakan oleh pejabat ASEAN pada World Conference on Human Rights di Wina pada bulan Juni 1993. Selanjutnya pernyataan yang sama dinyatakan kembali pada ASEAN Ministerial Meeting ke-26, di Singapura. Pada pertemuan itu enam Menteri Luar Negeri ASEAN membuat Joint Communique yang berisi menyambut baik Deklarasi dan Program Aksi sebagai hasil dari World Conference on Human Rights di Wina. Joint Communique menyatakan bahwa: ${ }^{16}$

1. HAM harus dilindungi dan dipromosikan dengan memperhatikan keadaan kebudayaan, ekonomi, dan politik;

2. perlindungan dan promosi HAM dalam masyarakat internasional harus memperhatikan prinsip-prinsip atas penghormatan kedaulatan, integritas wilayah dan non-interference atas urusan dalam negeri suatu negara;

3. kebebasan, kemajuan dan stabilitas nasional dengan mempromosikan keseimbangan antara hak-hak individu dan masyarakata;

4. kebutuhan untuk kemungkinan membentuk pengaturan tentang HAM pada tingkat regional dan sub-regional dalam keadaan tidak adanya aturan

15 ASEAN was established under the Bangkok Declaration in 8 August 1967 by Indonesia, Malaysia, the Philippines, Singapore, and Thailand with the aims and purposes to regional security, stability and economic cooperation among the members. The ASEAN has since developed the membership by admitting Brunei Darussalam in 1984, Vietnam in 1995, Laos, Myanmar in 1997 and Cambodia in 1999, <http://www.aseansec.org/ about_ASEAN.html>, diakses tanggal 4 Maret 2012.

16 Joint Communiqué of the Twenty-Sixth ASEAN Ministerial Meeting Singapore, 23-24 July 1993, para. 16-18, <http://www.aseansec.org/2009.htm>, diakses tanggal 4 Maret 2012. 
tersebut. Hal-hal inilah yang kemudian tercerminkan di dalam Piagam ASEAN yang dibentuk pada tahun 2007.

Komitmen ASEAN terhadap HAM mengendur setelah tahun 1995 karena bertambahnya keanggotaan ASEAN dengan bergabungnya Vietnam, Cambodia, Laos dan Myanmar, sehingga menyebabkan kemajukan politik di ASEAN. Ditambah lagi krisis finansial yang terjadi di negara-negara anggota ASEAN sehingga menciptakan suatu tantangan baru dan serius bagi ASEAN untuk lebih memfokuskan untuk memperkecil gap pembangunan diantara negara-negara anggota ASEAN. ${ }^{17}$

HAM mulai menjadi isu kembali di ASEAN ketika diadopsinya Vientiene Action Program (VAP), pada tahun 2004. VAP adalah tujuh tahun master plan untuk membangun Komunitas ASEAN yang didasarkan pada tiga pilar, yaitu political-security, economic dan socio-culture. VAP juga memasukan komitmen ASEAN untuk mebuat Piagam ASEAN sebagai bagian dari kerjasama politik dan keamanan termasuk diantaranya HAM untuk membentuk dan berbagi nilai diantara negara-negara ASEAN. ${ }^{18}$

\section{Peran Masyarakat Sipil dalam pembentukan AICHR}

Ketika negara-negara anggota ASEAN lambat dalam melakukan progres, masyarakat sipil mengambil alih inisiatif untuk mendorong komitmen ASEAN agar terwujudnya HAM. Pada tahun 1995, Human Rights Committee of LAWASIA, membentuk Working Group for an ASEAN Human Rights Mechanism (Working Group) yang terdiri atas beberapa kelompok kerja nasional termasuk wakil dari pemerintah, parlemen, akademik, dan lembaga swadaya masyarakat. ${ }^{19}$ Tujuan dari Working Group adalah terbentuknya mekanisme HAM di ASEAN. Untuk dapat mencapai tujuan tersebut Working Group melobi dan bernegosiasi dengan pejabat-pejabat di ASEAN dengan menggunakan hubungan mereka dengan pemerintah. Akhirnya Working Group menyampaikan Rancangan Agreement for the Establishment of the ASEAN Human Rights Commission. ${ }^{20}$

Kemudian setelah ASEAN mengumumkan komitmennya secara serius untuk membuat rancangan Piagam ASEAN, masyarakat sipil di kawasan Asia Tenggara berkinginan besar untuk bekerjasama dengan ASEAN. Tetapi perlu dicatat bahwa hubungan ASEAN dan masyarakat sipil telah terpecah belah. Di ASEAN terdapat tiga kelompok negara anggota yang berbeda dalam

${ }^{17}$ Termsak Chalermpalanupap, Promoting and Protecting Human Rights in ASEAN, $<\mathrm{http}$ ://www.aseansec.org/HLP-OtherDoc-2.pdf>, diakses tanggal 4 Maret 2012.

${ }^{18}$ Ibid.

19 The Working Group for an ASEAN Human Rights Mechanism, About Us, $<$ http://www.aseanhrmech.org/aboutus.html>, diakses tanggal 4 Maret 2012.

${ }^{20}$ Ibid. 
berhubungan dengan masyarakat sipil. Kelompok pertama adalah Indonesia dan Philipina yang lebih terbuka untuk berkonsultasi dan memberikan kesempatan berpartisipasi kepada masyarakat sipil dalam membuat keputusan. Kelompok kedua adalah Thailand dan Malaysia yang menerima partisipasi terbatas masyarakat sipil. Kelompok ketiga adalah Myanmar, Singapura, Vietnam, Laos, Kambodia dan Brunei yang menginginkan tidak adanya keterlibatan masyarakat sipil sama sekali. ${ }^{21}$ Perbedaan-perbedaan inilah yang mempengaruhi pembentukan ASEAN Human Rights Body.

Working Group dan masyarakat sipil yang mempunyai kepedulian terhadap HAM bergabung untuk melakukan lobi terhadap pemerintah negaranegara anggota ASEAN agar terbentuknya Human Rights Body. Di lain pihak masyarakat sipil yang lain dipimpin oleh Solidarity for Asian Peoples' Advocacy (SAPA) membentuk Task Force on ASEAN and Human Rights (SAPA Task Force) untuk tujuan yang sama. Dalam kaitan ini SAPA mempelopori National Human Rights Institutions (NHRIS) untuk terlibat dalam lobi kepada ASEAN. NHRIs ini terdiri dari empat Komisi Nasional HAM dari Indonesia, Malaysia, Philipina dan Thailand. ${ }^{22}$

Untuk kepentingan di atas ASEAN membentuk Eminent Person Group on ASEAN Charter (EPG) dengan otoritas merancang Piagam ASEAN. ${ }^{23}$ Dalam merancang Piagam ASEAN, EPG mengadakan dua pertemuan dengan masyarakat sipil, yaitu Working Group dan SAPA Task Force. Pada ASEAN Summit 2007, Laporan EPG mengenai Rancangan Piagam ASEAN disahkan dan diberikan kepada High Level Task Force (HLTF) untuk ditindak lanjuti. ${ }^{24}$ HLTF mengambil alih seluruh proses perancangan Piagam ASEAN. Selama proses ini HLTF mengadakan pertemuan dengan masyarakat sipil baik pada tingkat nasional maupun regional. Pada awalnya pertemuan ini adalah suatu indikasi yang sangat baik, tetapi dalam pertemuan-pertemuan tersebut diskusi dibatasi pada masalah-masalah prinsip-prinsip umum dan bukan pada masalah praktis sehingga proses ini terkesan sangat tidak transparan, detail dan inklusif. Pertemuan dengan masyarakat sipil hanya dapat dilakukan di beberapa negara anggota ASEAN saja, karena seperti dijelaskan di atas adanya perbedaan sikap di antara negara-negara anggota ASEAN terhadap masyarakat sipil. Rancangan

${ }^{21}$ Examining the engagement between civil society and ASEAN in the ASEAN Charter process, Thi Thu Huong Dang, Grin Verlag (Jan 2009), p. 19-25.

${ }^{22}$ Ginbar, hal.507. On SAPA see also Report Solidarity for Asian Peoples Advocacy (SAPA) General Forum <http://www.caramasia.org/enews/2007/march/inside/sapa/ sapa_report.pdf $>$, diakses tanggal 7 Maret 2012.

23 Eminent Persons Group (EPG) on the ASEAN Charter (2006) $<$ http://www.aseansec.org/21833.htm>, diakses tanggal 4 Maret 2012.

${ }^{24}$ High Level Task Force (HLTF) on the Drafting of the ASEAN Charter (2007) $<$ http://www.aseansec.org/21831.htm>, diakses tanggal 4 Maret 2012. 
instrumen, asupan dari negara anggota, masyarakat sipil terkait dengan rancangan Piagam ASEAN tidak pernah dibuka oleh HLTF. ${ }^{25}$

Pada tanggal 20 November 2007, ASEAN Summit di Singapura, ASEAN mengadopsi Piagam ASEAN yang kemudian berlaku pada tanggal 15 Desember 2008. Ini merupakan momentum penting bagi ASEAN yang telah berubah dari sebuah organisasi yang sangat longgar menjadi organisasi regional yang berdasarkan hukum. Piagam ASEAN memberikan kerangka kerja bagi ASEAN dan legal personality, ${ }^{26}$ membentuk proses kerjasama yang luas antar negara-negara anggota, ${ }^{27}$ memberikan dasar baru dalam pengambilan keputusan $^{28}$ dan memperjelas komitmen ASEAN untuk membentuk institusi HAM regional. ${ }^{29}$

Komitmen negara-negara anggota ASEAN untuk membentuk ASEAN Human Rights Body mendapat tanggapan skeptis dari masyarakat ASEAN. Menanggapi terbentuknya ASEAN Human Rights Body, Menteri Luar Negeri Singapur memberikan pernyataan tajam,

I'm not sure that it will have teeth, but it will certainly have a tongue. It will certainly have moral influence if nothing else.

(Saya tidak yakin (ASEAN Human Rights Body) akan memiliki gigi, tapi pasti memilik suara. ASEAN Human Rights Body pasti akan memiliki pengaruh moral tidak lebih.) ${ }^{30}$

Masyarakat sipil dan lembaga HAM internasional telah memberikan tanggapan skeptis terhadap sejauh mana ASEAN Human Rights Body mempunyai kewenangan untuk memberikan perlindungan terhadap warga negara atas pelanggaran HAM yang dilakukan oleh pemerintahan. ${ }^{31}$

${ }^{25}$ Ginbar, hal. 511.

${ }^{26}$ Chapter II, Article 3, The ASEAN Charter.

${ }^{27}$ Article 8-10, the ASEAN Charter.

${ }^{28}$ Article 8, Ibid.

${ }^{29}$ Article 14 , Ibid.

30 International Herald Tribune, Quoted in "Myanmar crisis to dominate ASEAN summit, but free trade, climate, also high on agenda", 17 November 2007, at $<$ http://www.iht.com/articles/ap/2007/11/18/asia/AS-GEN-ASEAN.php>, diakses tanggal 18 Maret 2012.

31 Manila Bulletin Publishing Corporation, Manila vows to push for human rights http://www.mb.com.ph/node/226127/manila-vow>, diakses tanggal 4 Maret 2012. 


\section{Pembentukan ASEAN Intergovernmental Commission on Human Rights}

Pasal 14 dari Piagam ASEAN menyatakan bahwa pembentukan ASEAN Human Rights Body harus sesuai dengan tujuan dan prinsip dari Piagam ASEAN terkait promosi dan perlindungan HAM dan kebebasan dasar. Pertemuan Menteri Luar Negeri ASEAN diberi tugas untuk mengkaji dan membuat Human Rights Body Term of Reference (TOR) diberikan kepada, yang kemudian menunjuk High Level Panel (HLP) untuk melaksanakan tugas tersebut. Pada Oktober 2009, TOR pembentukan ASEAN Human Rights Body diadopsi pada ASEAN Summit ke-15 di Thailand dan ASEAN Interngovernmental Commission on Human Rights (AICHR) terbentuk. ${ }^{32}$

Dalam TOR dinyatakan bahwa tujuan dari AICHR adalah "mempromosikan HAM dan hak-hak dasar dari warga ASEAN dalam konteks regional, dengan mempertimbangkan keunikan dan saling menghormati atas perbedaan latar belakang sejarah, budaya dan agama serta memperhatikan keseimbangan antara hak dan tanggung jawab". 33 Berdasarkan praktek, terdapat prinsip yang menjadi rujukan AICHR yaitu ASEAN Way. ASEAN Way adalah praktek bagaimana ASEAN melaksanakan kerjasama di antara negara-negara anggota ASEAN. Doktrin sentral dari ASEAN Way adalah kemerdekaan, kedaulatan, kesejajaran, integritas wilayah dan identitas kebangsaan dari seluruh negara-negara anggota ASEAN, tidak campur tangan urusan dalam negeri, penghormatan terhadap hak setiap negara anggota yang bebas dari campur tangan eksternal, subversi, dan paksaan serta penghormatan atas perbedaan budaya, bahasa dan agama dari warga ASEAN dengan memperhatikan persamaan nilai dalam semangat perbedaan dalam persatuan. ${ }^{34}$ Secara singkat $A S E A N$ Way adalah kerjasama melalui saling pengertian secara informal yang menekankan kewajiban tanpa keterikatan berdasarkan hukum di antara negara-negara ASEAN. ${ }^{35}$

AICHR sebagaimana tertera di dalam TOR, dideskripsikan sebagai badan inter-pemerintah ${ }^{36}$ dan konsultasi, yang anggotanya merupakan perwakilan dari negara-negara anggota ASEAN. ${ }^{37}$ Pengambilan keputusan di AICHR

${ }^{32}$ Cha-Am Hua Hin Declaration On The Intergovernmental Commission On Human Rights, <http://www.aseansec.org/documents/Declaration-AICHR.pdf $>$, diakses tanggal 4 Maret 2012.

${ }^{33}$ Art. $1.1-1.4$, TOR AICHR.

${ }^{34}$ Article 2, TOR AICHR.

35 The ASEAN Way And The Rule Of Law, Address by Rodolfo C. Severino, Secretary-General of the Association of Southeast Asian Nations, at the International Law Conference on ASEAN Legal Systems and Regional Integration sponsored by the Asia-Europe Institute and the Faculty of Law, University of Malaya Kuala Lumpur, 3 September 2001.

${ }^{36}$ Article 3, TOR AICHR. 
didasarkan pada konsultasi dan konsensus sesuai Pasal 20 dari Piagam ASEAN. ${ }^{38}$ TOR juga memberikan AICHR kewenangan untuk mempromosikan dan melindungi HAM. ${ }^{39}$ Selanjutnya, yang sangat signifikan yang diberikan oleh TOR kepada AICHR adalah tugas untuk merancang ASEAN Human Rights Declaration sebagai sistem hukum HAM regional yang mengikat. ${ }^{40}$

Masyarakat sipil di ASEAN menyampaikan beberapa kritik terhadap TOR AICHR, pertama prinsip-prinsip di ASEAN dimungkinkan menjadi penghalang bagi AICHR untuk melakukan investigasi terhadap pelanggaran HAM di negara anggota. ${ }^{41}$ Kedua, perwakilan yang ditunjuk oleh negaranegara anggota ASEAN adalah pejabat negara atau mantan pejabat negara dengan pengecualian perwakilan dari Indonesia, seorang aktivis HAM dan Thailand, seorang akademisi. ${ }^{42}$ Ketiga, pengambilan keputusan melalui konsensus berarti setiap negara dapat menolak kritik yang ditujukan kepada negaranya, sehingga dapat mengakibatkan deadlock atau pengadopsian posisi yang lemah atas isu HAM. ${ }^{43}$ Masyarakat sipil merasa bahwa kewenangan AICHR dalam perlindungan HAM sangat lemah, walaupun masyarakat sipil telah melakukan lobi untuk menjadikan AICHR sebagai sebuah institusi yang lebih mempunyai gigi dan kewenangan untuk melakukan ivestigasi terhadap pengaduan individual dan situasi HAM di suatu negara. ${ }^{44}$

\section{Peran Masyarakat Sipil dalam Hukum Internasional}

Hubungan yang dinamis dalam masyarakat internasional dalam tiga dekade terakhir telah memberikan ruang bagi aktor selain negara untuk mengambil bagian dalam membentuk hukum internasional salah satu aktornya adalah masyarakat sipil sebagai representasi dari pendapat umum. Partisipasi publik dalam masyarakat internasional adalah suatu hal yang tidak dapat dihindari dalam hubungan internasional nasional yang makin kompleks. Fenomena globalisasi dan kebutuhan untuk mencari solusi atas permasalahan

${ }^{37}$ Article 5, TOR AICHR.

${ }^{38}$ Article 6.1, TOR AICHR.

${ }^{39}$ Article 4.1, TOR AICHR.

${ }^{40}$ Article 4.2, TOR AICHR.

${ }^{41}$ James Munro, The Relationship between the origins and regime design of the ASEAN Intergovernmental Commission on Human Rights (AICHR), The International Journal of Human Rights, 20 October 2010, p. 4-5.

${ }^{42}$ Amnesty International Public Statement, ASEAN's new body must protect and promote human rights, <http://www.amnesty.org/en/news-and-updates/news/asean-new-bodymust-protect-promote-human-rights-20090721>, diakses tanggal 22 Maret 2012.

${ }^{43}$ Ginbar, hal. 514-515.

${ }^{44}$ Ibid. 
global telah memberikan kewenangan partisipasi publik dalam hukum internasional. ${ }^{45}$ Seringkali, solusi global berarti keharusan untuk melakukan perubahan mendasar dan komprehensif terhadap kebijakan internasional dan hukum. ${ }^{46}$ Sehingga hal ini yang mempunyai dampak terhadap kebijakan domestik yang mempengaruhi hak dan kewajiban individu di suatu negara. Terkait dengan perkembangan baru ini, fokus dari masyarakat sipil telah berkembang dari tingkat nasional ke tingkat internasional yang bertujuan meberikan pengaruh yang lebih luas.

Masyarakat sipil secara reguler telah berpartisipasi dalam berbagai macam kegiatan di dalam masyarakat internasional melalui konferensi multilateral, membuat laporan atas pelaksanaan perjanjian internasional, dan juga berperan dalam penyelesaian sengketa internasional melalui amicus curiea, mempromosikan pembentukan organisasi internasional dan melakukan lobi terhadap pemerintah dari berbagai nergara untuk mendapatkan dukungan dalam membuat aturan internasional yang lebih kuat. ${ }^{47}$ Beberapa contoh keterlibatan civil society dalam kancah internasional adalah konferensi yang mengadopsi Convention on the Prohibition of the Use, Stockpiling, Production and Transfer or Anti-Personnel Mines and on Their Destruction, 1997, Convention on Cluster Munitions, 2008 dan contoh yang lain adalah Torture Convention, 1984, Convention on the Rights of the Child, 1990, dan Rome Statute of the International Criminal Court, $1999{ }^{48}$

Masyarakat sipil telah memberikan kontribusi terhadap perkembangan dalam hukum internasional melalui interpretasi perjanjian internasional, penerapan hukum internasional dan penegakan hukum internasional. ${ }^{49}$ Masyarakat sipil juga mengambil peran dalam penyelesaian sengketa internasional melalui pengadilan internasional. Ini dilakukan oleh masyarakat sipil melalui Mahkamah Internasional, Tribunal Internasional Hak Asasi Manusia, WTO Dispute Settlement dan Arbitrase Internasional. Salah satu civil society institusi, Non-governmental Organization/lembaga swadaya masyarakat (NGO). NGO telah melakukan kontribusi melalui amicus curiea dalam pengadilan internasional. Amicus curiae adalah penyampaian laporan tertulis yang disampaikan ke pengadilan atas perkara tertentu yang tidak

45 P. Van den Bossche, Non-Governmental Organization and the WTO: Limits to Involvement?, Redesigning The World for the Twenty First Century, Ed. Debra Steger (2010), $<$ http://www.idrc.ca/en/ev-151624-201-1-DO_TOPIC.html>, diakses tanggal 18 Maret 2012

${ }^{46}$ Ibid.

47 Steve Charnovitz, Non-governmental Organizations and International Law, "The American Journal of International Law", Vol 100, No. 2 (April 2006).

48 Jean d'Aspremont, "International Law-Making by Non-State Actors: Changing the Model or Putting the Phenomenon into Perspective?", Non-State Actor Dynamics in International Law, (Math Noothmann ed., Ashgate, August 2010).

49 Ibid. Lihat juga, Lung-Chu Chen, "An Introduction to Contemporary International Law: A Policy Oriented Perspective”, Ch. 4, (2nd ed. 2000). 
terbatas pada masalah hukum yang menjadi sengketa di pengadilan atau di luar dari masalah hukum yang disengketakan. Masalah hukum ini sebenarnya bisa saja kemukan oleh hakim yang menangani perkari tersebut. ${ }^{50}$ Tribunal internasional telah membuat prosedur dalam penyampaian amicur curiae ini oleh masyarakat sipil untuk menyampaikan informasi atau pernyataan atas perkara yang disidangkan. Namun sampai saat ini Mahkamah Internasional tetap tertutup atas penyampain amicus curiae. ${ }^{51}$

Sejak pembentukan Perserikan Bangsa Bangsa (PBB) partisipasi masyarakat sipil telah ada di dalam Pasal 71 Piagam PBB, yang menyatakan,

The Economic and Social Council may make suitable arrangements for consultation with non-governmental organizations.

Berdasarkan pasal ini pada 25 Juli 1996, Dewan Ekonomi Sosial PBB mengadopsi Resolusi 1996/31 tentang "Consultative Relationship between the United Nations and Non-Governmental Organizations". Resolusi ini memberikan hak dan status kepada NGO dalam keterlibatannya di Dewan Ekonomi Sosial PBB. NGO mempunyai tiga tipe status berdasarkan resolusi ini, (i) general consultative status, (ii) special consultative status, (iii) penyertaan dalam roster, dan masing-masing mempunyai hak dan kewajiban yang berbeda. Dalam kerangka PBB, berbagai bentuk keterlibatan NGO dengan badan-badang PBB, program, penyertaan, sekretarian, dan kadang terlibat dalam konsultasi dengan negara anggota $\mathrm{PBB} .{ }^{52}$

Partisipasi publik dalam hukum internasional meningkat sejak tahun 1990. Interpretasi yang luas atas Pasal 71 Piagam PBB mendorong keterlibatan masyarakat sipil dalam hukum internasional dan kegiatan PBB. Alasan meningkatnya keterlibatan masyarakat sipil karena solusi yang diberikan oleh negara dan organisasi internasional yang sering bersifat eksklusif, sehingga membuat solusi menjadi tidak layak dan efektif dalam menyelesaikan permasalahan global seperti HAM dan lingkungan tanpa adanya partisipasi publik.

\section{Peran Masyarakat Sipil dalam Badan HAM Internasional}

Dalam masalah HAM, masyarakat sipil telah memainkan peranan yang penting terkait dengan badan yang telah dibentuk berdasarkan perjanjian

${ }^{50}$ Dinah Shelton, The Participation of Nongovernmental Organization in International Judicial Proceeding, "88 American Journal of International Law", October 1994, p. 611.

${ }^{51}$ Ibid.

${ }^{52}$ United Nations Economic and Social Council, Consultative Relationship between the United Nations and Non-Govenrmental Organizations, (ECOSOC Resolution 1996/312), UN Document E/1996/31, 25 July 1996, <http://www.un.org/documents/ecosoc/res/1996/eres199631.htm>, diakses tanggal 4 Maret 2012. 
internasional HAM. Ketua dari Treaty Bodies membuat pernyataan bersama yang menyatakan,

... once again that non-governmental organizations play a vital role in supplying the treaty bodies with documentation and other information on human rights development that is extremely useful for their monitoring activities and that each treaty bodies should consider how best to monitor and facilitate this role. ${ }^{53}$

... sekali lagi NGO memainkan peranan yang vital dalam memberikan dokumentasi dan informasi perkembangan HAM kepada Treaty Bodies yang berguna dalam melakukan pengawasan dan setiap badan HAM harus mempertimbangkan keterlibatan NGO dalam memonitor dan memberikan fasilitas atas peran mereka.(Terjemahan Penulis)

Selanjutnya para ketua Treaty Bodies mendorong NGO untuk terus berperan serta aktif dalam menilai kerja dari Treaty Bodies. Sir Nigel Rodley, menganggap NGO berperan penting dalam memberikan informasi kepada anggota badan HAM, sehingga memastikan mereka dalam posisi untuk memberikan pertanyaan atas laporan yang diberikan oleh pejabat negara. ${ }^{54}$

\section{Hubungan Treaty Bodies dengan Masyarakat Sipil berdasarkan Instrument Hukum}

Treaty Bodies mempunyai pendekatan yang berbeda terhadap partisipasi publik. Dengan pengecualian Committee on Economic, Social, and Culture Rights (CESCR), Treaty Bodies yang lain bukanlah badan yang berada di bawah United Nations Economic Social Council (UN ECOSOC), sehingga pengaturan mengenai konsultasi antara NGO dan badan HAM tidak berlaku. ${ }^{55}$ UN ECOSOC membentuk CESCR yang berbeda dengan Treaty Bodies lainnya, ${ }^{56}$ dengan mendudukan CESCR sebagai subsidiary organ dari UN ECOSOC. CESCR telah membuat prosedur untuk berhubungan dengan masyarakat sipil, prosedur ini telah diadopsi pada tahun 1993 yang kemudian diperbaharui dengan lampiran

${ }^{53}$ A/51/482, Human Rights Question, 11 October 1996, para. 35-36, see also A/52/507 21 October 1997, para. 61

54 Anna-Karin Lindblom, "Non-Governmental Organizations in International Law", (UK: Cambrige University Press, 2005), p. 395.

${ }^{55}$ Ibid.

56 Economic and Social Council Resolution 1985/17, Review of the composition, organization and administrative arrangements of the Sessional Working Group of Governmental Experts on the Implementation of the International Covenant on Economic, Social and Cultural Rights, 28 May 1985. 
petunjuk teknis pada tahun $2000 .^{57}$ NGO mempunyai akses terhadap semua proses monitoring yang dilakukan oleh CESCR dengan status seperti di dalam UN ECOSOC.

Committee on the Rights of the Child (CRC) mempunyai kewenangan untuk memonitor penerapan Convention on the Rights of the Child dan dua protokolnya. Berdasarkan Pasal 45 Convention on the Rights of the Child, CRC mempunyai dasar hukum untuk melibatkan NGO dalam proses yang berlangsung di CRC, seperti dinyatakan:

In order to foster the effective implementation of the Convention and to encourage international co-operation in the field covered by the Convention:

1. .... The Committee may invite the specialized agencies, the United Nations Children's Fund and other competent bodies as it may consider appropriate to provide expert advice on the implementation of the Convention in areas falling within the scope of their respective mandates.

Menurut pendapat CRC kata-kata "other competent bodies" termasuk NGO. Interpretasi ini mengizinkan NGO untuk berpartisipasi dalam pelaksanaan dari Kovensi Hak Anak. Hal penting juga NGO juga mempunyai peran yang sangat penting dalam perancangan Convention on the Rights of the Child ini sejak awal. ${ }^{58}$ NGO telah berkordinasi dan berkonsentrasi dengan membuat Kelompok Kerja NGO untuk dapat bekerja secara baik dengan CRC. Berdasarkan permintaan dari CRC $^{59}$ Kelompok kerja NGO dapat terlibat secara teratur dalam pra-sesi kelompok kerja CRC yang mengagendakan laporan dari negara. NGO telah membantu anggota CRC dalam mengulas dan membuat daftar pertanyaan yang akan didiskusikan dengan negara pihak. NGO juga dapat memberikan pernyataan tertulis kepada CRC.

Committee on the Protection of the Rights of All Migrant Workers and Members of their Families (Committee on Migrant Worker) sebagai pengawas terhadap pelaksanaan Convention on the Protection of the Rights of All Migrant Workers and Members of their Families (Convention on Migrant Worker) terhadap negara pihak dari Konvensi ini. Dalam melakukan kewenangannya Committee on Migrant Worker bekerjasama dengan NGO didasarkan pada Pasal 74 (4) Convention on Migrant Worker yang menyatakan bahwa,

${ }^{57}$ E/C.12/2000/6, Participation of non-governmental organizations in the Committee on Economic, Social and Cultural Rights, 7 July 2000. <http:/www2.ohchr.org/english/ bodies/cescr/NGOs.htm>, diakses tanggal 28 januari 2012.

${ }^{58}$ Lindbolm, hal. 405.

${ }^{59}$ Ibid. 
The Committee may invite the specialized agencies and organs of the United Nations, as well as intergovernmental organizations and other concerned bodies to submit, for consideration by the Committee, written information on such matters dealt with in the present Convention as fall within the scope of their activities.

Kata-kata "other concerned bodies" sesuai dengan Rule 28 dari Rule of Procedure Committee on Migrant Worker, termasuk Komisi Nasional HAM, NGO dan lembaga-lembaga lainnya. ${ }^{60}$

Committee Against Torture (CAT) berwenang mengawasi pelaksanaan atas Convention against Torture and other Cruel, Inhuman or Degrading Treatments yang dilakukan oleh negara pihak. Sebagai bagian dari proses terhadap laporan negara pihak mengenai pelaksanaan dari Konvensi, CAT menerima informasi dari NGO tentang pelaksanaan yang dilakukan oleh negara pihak. Untuk dapat melakukan ini CAT mendasarkan dari praktik yang terdapat dalam Rule of Prosedure, Rule 62 , yang menyatakan: ${ }^{61}$

The Committee may invite...NGOs in consultative status with the ECOSOC to submit to it information, documentation and written statements, as appropriate, relevant to the Committee's activities under the Convention.

Sehubungan dengan itu Konvensi menyatakan bahwa:

If the Committee receives reliable information which appears to it to contain well-founded indications that torture is being systematically practiced in the territory of a state party. The Committee shall invite that state to co-operate in the examination of the information and to this end to submit observations with regard to the information concerned. ${ }^{62}$

Dengan demikian jelas bahwa dalam melakukan kegiatannya jika memang dibutuhkan suatu informasi maka CAT dapat mengundang NGO untuk kepentingannya.

Committee on the Elimination of Discrimination Against Women mempunyai kewenangan untuk mengawasi pelaksanaan negara pihak atas Convention on The Elimination All forms of Discrimination against Women. Mengenai hubungan Committee on the Elimination of

${ }^{60} \mathrm{HRI} / \mathrm{Gen} / 3 /$ Rev.1/Add.1, Addendum Compilation Of Rules Of Procedure Adopted By Human Rights Treaty Bodies, 7 May 2004, Rule No. 28.

${ }^{61}$ CAT/C/3/Rev.4, Rule Procedure Committee Against Torture, 9 August 2002, Rule 62.

${ }^{62}$ Ibid. 
Discrimination Against Women dengan NGO, Rule of Prosedure menyatakan:

Representatives of non-governmental organizations may be invited by the Committee to make oral or written statements and to provide information or documentation on areas relevant to the Committee's activities under the Convention to meetings of the Committee or the pre-session working group. ${ }^{63}$

Dengan jelas disebutkan bahwa perwakilan NGO dapat diundang oleh Committee on the Elimination of Discrimination Against Women untuk menyampaikan pernyataan secara tertulis atau lisan dan memberikan informasi dan dokumentasi dalam pre-session working group yang membahas mengenai laporan negara pihak.

\section{Hubungan Treaty Bodies dengan Masyarakat Sipil berdasarkan pada Praktek}

Tetapi tidak semua Treaty Bodies mempunya dasar hukum utama berdasarkan konvensi untuk pelibatan masyarakat sipil. Karena itu, untuk melibatkan masyarakat sipil, Treaty Bodies ini membuat dasar hukum tambahan melalui Rule of Procedures dan praktek untuk melibatkan partisipasi publik.

Human Rights Committee berdasarkan International International Covenant on Civil and Political Rights (ICCPR) dan Rule of Procedurenya tidak mempunyai dasar untuk bekerjasama dengan NGO. Walaupun, Rule 62 dari Rule of Procedure ${ }^{64}$ memberikan kewenangan bagi Human Rights Committee untuk membentuk kelompok kerja dalam membahas laporan dari negara pihak. Berdasarkan laporan Human Rights Committee kepada United Nations General Assembly selama kelompok kerja ini melakukan pembahasan, kelompok kerja juga membuat pertemuan dan diskusi dengan perwakilan NGO untuk mendapatkan informasi. ${ }^{65}$

${ }^{63} \mathrm{~A} / 56 / 38$ as amended by A/62/38 (2001), Rules of Procedure of the Committee on the Elimination of Discrimination Against Women, Rule 47.

${ }^{64}$ CCPR/C/3/Rev.8, Rules of Procedure of the Human Rights Committee, 22 September 2005, Rule 62

1. The Committee may, taking into account the provisions of the Covenant and the Protocol, set up such subcommittees and other ad hoc subsidiary bodies as it deems necessary for the performance of its functions, and define their composition and powers.

2. Subject to the provisions of the Covenant and the Protocol and unless the Committee decides otherwise, each subsidiary body shall elect its own officers and may adopt its own rules of procedure. Failing such rules, the present rules of procedure shall apply mutatis mutandis.

${ }^{65}$ Lindblom, p. 396, Lihat juga: "The Report Human Rights Committee", (Vol. I) A/64/40, 1 July 2009, para 13. 
Kemudian NGO pun dapat menghadiri pertemuan kelompok kerja ketika membahas laporan dengan perwakilan negara pihak, walaupun mereka tidak dapat ikut serta dalam dialog tersebut.

Committee on the Elimination of Racial Discrimination adalah Komite yang mengawasi pelaksanaan oleh negara-negara pihak dari Convention on the Elimination of Racial Discrimination. Committee on the Elimination of Racial Discrimination tidak mempunyai dasar hukum untuk menerima atau melibatkan NGO dalam proses pembahasan laporan dari negara pihak. Pada 1991, Committee on the Elimination of Racial Discrimination memutuskan bahwa sebagai ahli yang independen, Komite mempunyai akses terhadap segala bentuk informasi dari berbagai sumber, baik pemerintah dan NGO selam melakukan pembahasan laporan negara pihak ${ }^{66}$ Karena Komite tidak mempunyai dasar hukum untuk berhubungan dengan NGO, Komite mengembangkan partisipasi NGO melalui pratek. Committee on the Elimination of Racial Discrimination mulai menerima informasi dari NGO khususnya yang diberikan oleh kelompok NGO. Sejak Pertemuan ke-50 1995, Komite memulai beberapa pertemuan dengan $\mathrm{NGO} .{ }^{67}$

Committee on the Elimination of Racial Discrimination juga mengembangkan praktek early warning system terhadap kasus-kasus pelanggaran yang penting. Untuk dapat melaksanakan pekerjaan ini Komite membutuhkan informasi dari berbagai macam sumber, termasuk NGO. NGO juga terlibat dalam diskusi dan pertemuan tematik yang dilakukan oleh Komite. NGO juga berpartisipasi ketika Komite menerima pengaduan individu yang menjadi korban pelanggaran Kovensi.

\section{Kesimpulan dan Saran}

Perdebatan mengenai efektifitas AICHR dalam menangani permasalahan HAM di wilayah Asia Tenggara berlangsung di kalangan masyarakat sipil. Setahun setelah pembentukan AICHR, masyarakat sipil mengkritik AICHR sebagai kedok untuk memperbaiki citra negara-negara anggota ASEAN. Walaupun kinerja AICHR dianggap sebagai perkembangan yang positif, tetapi beberapa kinerjanya mengecewakan dan mengkhawatirkan. AICHR terus berkembang, walaupun terdapat keraguan atas kinerjanya, bukan berarti AICHR tidak akan berkembang. AICHR dapat mengambil keuntungan dari masyarakat sipil dalam mengembangkan prosedur dan pelaksanaan mandat

\footnotetext{
${ }^{66} \mathrm{Ibid}$,. According to her interview with Peter Nobel, former member of the Committee on the Elimination of Racial Discrimination, hal. 402-403.

${ }^{67}$ A/48/18 (1993), ANNEX III Prevention of racial discrimination, including early warning and urgent procedures: working paper adopted by the Committee on the Elimination of Racial Discrimination.
} 
yang diberikan dan mengambil pengalaman dari organisasi HAM lainnya baik nasional maupun internasional.

Seperti halnya Treaty Bodies mengakui pentingnya kontribusi dari masyarakat sipil dalam implementasi dan pengawasan atas kewajiban negara yang diatur di dalam konvensi-konvensi yang ada. Hanya saja ketidakcukupan aturan dalam hukum yang tidak dijadikan alasan oleh Treaty Bodies dalam pelibatan masyarakat sipil dalam pengabilan keputusan di dalam masyarakat internasional. Inilah seharusnya langkah yang harus diambil oleh AICHR untuk mengembangkan mekanisme HAM-nya, bukan kemudian bersembunyi dibalik keterbatasan TOR AICHR. 


\section{Daftar Pustaka}

\section{Buku}

Charter of the Association of Southeast Asian Nations.

Chen, Lung-Chu. An Introduction to Contemporary International Law: A Policy Oriented Perspective, Ch. 4, 2nd ed. 2000.

Compilation Of Rules Of Procedure Adopted By Human Rights Treaty Bodies, 7 May 2004.

d'Aspremont, Jean. International Law-Making by Non-State Actors: Changing the Model or Putting the Phenomenon into Perspective?, Non-State Actor Dynamics in International Law, Math Noothmann ed., Ashgate, August 2010.

Economic and Social Council Resolution 1985/17, Review of the composition, organization and administrative arrangements of the Sessional Working Group of Governmental Experts on the Implementation of the International Covenant on Economic, Social and Cultural Rights, 28 May 1985.

Lindblom, Anna-Karin. Non-Governmental Organizations in International Law, UK: Cambrige University Press, 2005.

Rule Procedure Committee Against Torture, 9 August 2002.

Rules of Procedure of the Committee on the Elimination of Discrimination Against Women.

Rules of Procedure of the Human Rights Committee, 22 September 2005.

The ASEAN Way And The Rule Of Law, Address by Rodolfo C. Severino, Secretary-General of the Association of Southeast Asian Nations, at the International Law Conference on ASEAN Legal Systems and Regional Integration sponsored by the Asia-Europe Institute and the Faculty of Law, University of Malaya Kuala Lumpur, 3 September 2001.

The Report Human Rights Committee, (Vol. I) A/64/40, 1 July 2009.

Term of Reference of ASEAN Intergovernmental Commission on Human Rights (TOR AICHR).

\section{Jurnal/Makalah/Artikel}

Charnovitz, Steve. "Non-governmental Organizations and International Law", The American Journal of International Law, Vol 100, No. 2 April 2006. 
Huong Dang, Thi Thu, and Grin Verlag. "Examining the engagement between civil society and ASEAN in the ASEAN Charter process", (Jan 2009): 19-25.

Ginbar, Yuval. "Human Rights in ASEAN- Setting Sail or Treading Water?", Human Rights Law Review, 10:3 (2010): 514-515.

Munro, James. "The Relationship between the origins and regime design of the ASEAN Intergovernmental Commission on Human Rights (AICHR)", The International Journal of Human Rights, 20 October 2010: 4-5.

Shelton, Dinah. "The Participation of Nongovernmental Organization in International Judicial Proceeding", 88 American Journal of International Law, October 1994: 611.

\section{Internet}

"Amnesty International Public Statement", <http://www.amnesty.org/en/ news-and-updates/news/asean-new-body-must-protect-promotehuman-rights-20090721>, diakses tanggal 28 Januari 2012.

"ASEAN Human Rights Commission Stumbles At First Hurdle", $<$ http://theonlinecitizen.com/2010/03/asean-human-rightscommission-stumbles-at-first-hurdle/>, diakses tanggal 28 Januari 2012.

"High Level Task Force (HLTF) on the Drafting of the ASEAN Charter", (2007) <http://www.aseansec.org/21831.htm>, diakses tanggal 4 Maret 2012.

"Report Solidarity for Asian Peoples Advocacy (SAPA) General Forum",

<http://www.caramasia.org/enews/2007/march/inside/sapa/sapa_rep ort.pdf $>$, diakses tanggal 28 Januari 2012.

Amnesty International Public Statement, "ASEAN's new body must protect and promote human rights", <http://www.amnesty.org/en/ news-and-updates/news/asean-new-body-must-protect-promotehuman-rights-20090721>, diakses tanggal 22 Maret 2012.

Chalermpalanupap, Termsak. "Promoting and Protecting Human Rights in ASEAN", <http://www.aseansec.org/HLP-OtherDoc-2.pdf>, diakses tanggal 4 Maret 2012.

den Bossche, P. Van. Non-Governmental Organization and the WTO: Limits to Involvement?, Redesigning The World for the Twenty First Century, Ed. Debra Steger (2010), <http://www.idrc.ca/en/ev151624-201-1-DO_TOPIC.html>, diakses tanggal 18 Maret 2012 
Eminent Persons Group (EPG) on the ASEAN Charter (2006) $<$ http://www.aseansec.org/21833.htm>, diakses tanggal 4 Maret 2012.

Hua Hin, Cha-Am. "Declaration On The Intergovernmental Commission On Human Rights", <http://www.aseansec.org/documents/ Declaration-AICHR.pdf>, diakses tanggal 4 Maret 2012.

International Herald Tribune, 17 November 2007, at $<$ http://www.iht.com/articles/ap/2007/11/18/asia/AS-GENASEAN.php>, diakses tanggal 18 Maret 2012.

Manila Bulletin Publishing Corporation, "Manila Vows To Push For Human Rights", <http://www.mb.com.ph/node/226127/manilavow>, diakses tanggal 4 Maret 2012.

The Working Group for an ASEAN Human Rights Mechanism, "About Us", <http://www.aseanhrmech.org/aboutus.html>, diakses tanggal 14 Febuari 2012.

United Nations Economic and Social Council, Consultative Relationship between the United Nations and Non-Govenrmental Organizations, (ECOSOC Resolution 1996/312), UN Document E/1996/31, 25 July 1996, <http://www.un.org/documents/ecosoc/res/1996/eres199631.htm>, diakses tanggal 4 Maret 2012.

$<$ http://www.aseansec.org/2009.htm>, diakses tanggal 4 Maret 2012. 